\section{BMJ Paediatrics Open}

\title{
Causes of death in critically ill paediatric patients in Japan: a retrospective multicentre cohort study
}

\author{
Tadashi Ishihara, ${ }^{\circledR}$ Hiroshi Tanaka
}

To cite: Ishihara T, Tanaka H. Causes of death in critically ill paediatric patients in Japan: a retrospective multicentre cohort study. BMJ Paediatrics Open 2019;3:e000499. doi:10.1136/ bmjpo-2019-000499

Received 3 April 2019 Revised 6 July 2019 Accepted 12 July 2019
Check for updates

(C) Author(s) (or their employer(s)) 2019. Re-use permitted under CC BY-NC. No commercial re-use. See rights and permissions. Published by BMJ.

Emergency and Critical Care Medicine, Juntendo University Urayasu Hospital, Urayasu, Chiba, Japan

Correspondence to Dr Tadashi Ishihara; ta-shi. 0517@hotmail.co.jp

\section{ABSTRACT}

Objectives The primary objective is to clarify the clinical profiles of paediatric patients who died in intensive care units (ICUs) or paediatric intensive care units (PICUs), and the secondary objective is to ascertain the demographic differences between patients who died with and without chronic conditions.

Methods In this retrospective multicentre cohort study, we collected data on paediatric death from the Japanese Registry of Pediatric Acute Care (JaRPAC) database. We included patients who were $\leq 16$ years of age and had died in either a PICU or an ICU of a participating hospital between April 2014 and March 2017. The causes of death were compared between patients with and without chronic conditions.

Results Twenty-three hospitals participated, and 6199 paediatric patients who were registered in the JaRPAC database were included. During the study period, 126 (2.1\%) patients died (children without chronic illness, $n=33$; children with chronic illness, $n=93$ ). Twenty-five paediatric patients died due to an extrinsic disease, and there was a significant difference in extrinsic diseases between the two groups (children without chronic illness, $15(45 \%)$; children with chronic illness, $10(11 \%) ; p<0.01)$. Cardiovascular disease was the most common chronic condition $(27 / 83,29 \%)$. Eighty-three patients $(85 \%)$ in the chronic group died due to an intrinsic disease, primarily congenital heart disease $(14 / 93,15 \%)$, followed by sepsis $(13 / 93,14 \%)$.

Conclusions The majority of deaths were in children with a chronic condition. The major causes of death in children without a chronic illness were due to intrinsic factors such as cardiovascular and neuromuscular diseases, and the proportion of deaths due to extrinsic causes was higher in children without chronic illness.

\section{INTRODUCTION}

In recent years, the survival rate for critically ill paediatric patients has improved. Many countries now have specialised paediatric intensive care units (PICUs), which may contribute to the improved survival rates for critically ill paediatric patients. ${ }^{1-7}$ In more economically developed countries, the mortality rate in PICUs has decreased substantially from approximately $9 \%$ to $3 \% .{ }^{8}$ According to a few international cohort studies, acute mortality rates vary from $2 \%$ to $3 \%$ during intensive care

\section{What is known about the subject?}

- Concentration of critically ill paediatric patients in tertiary paediatric intensive care units (PICUs) contributes to improved survival outcomes for severely ill paediatric patients.

- Overall, the mortality rate for critically ill paediatric patients at PICUs or intensive care units across multiple centres is on average $2 \%-3 \%$.

\section{What this study adds?}

The main finding of this study is that $98 \%$ of patients aged $\leq 16$ years admitted to critical care in Japan survived.

- The proportion of deaths due to extrinsic disease was higher in children without chronic illness.

- The majority of deaths were in children with a chronic condition.

stays. ${ }^{9-17}$ The mortality rate for critically ill paediatric patients in Japan has been reported from a single centre, and multicentre studies have been limited primarily because no databases have been specifically designated for critically ill paediatric patients. ${ }^{18}$

The Ministry of Health, Labour and Welfare in Japan annually reports cause of death according to age; however, their reports only provide an approximate diagnosis and number of deaths. According to these official reports, the primary cause of death in neonates and toddlers is congenital abnormalities and malignant neoplasms. Previous reports from European countries show cardiovascular and neuromuscular diseases as the most frequent causes of death in critically ill paediatric patients in PICUs or intensive care units (ICUs). ${ }^{13} 19$ However, no study to date has investigated the causes of death in critically ill paediatric patients using a multicentre database.

Paediatric deaths are rare; hence, there are few reports on the causes of death in paediatric emergency and critical care 
departments. Furthermore, the different causes of death between children without chronic illness and children with chronic conditions have not been determined. This study aimed to describe the clinical profiles of critically ill paediatric patients who had died in the PICUs or ICUs of participating hospitals and ascertain the demographic differences between patients with and without chronic conditions.

\section{METHODS}

\section{Data set}

The Japanese Registry of Pediatric Acute Care (JaRPAC) initiated a database in April 2014 that aimed to evaluate critically ill paediatric patients and reduce their mortality rate. JaRPAC is a multicentre clinical database of PICU or ICU paediatric patients founded by the Japanese Society for Emergency Medicine. The JaRPAC database contains anonymised information regarding patient demographics and admissions, scoring systems for severity and mortality, ${ }^{20}$ treatment, and outcomes. Paediatric patients $\leq 16$ years old in ICUs or PICUs are eligible for this registry, and the registry data are per capita. The data were collected until discharge from ICU or PICU. The National Center for Child Health and Development is the primary institute that manages the registry data, and hospitals that are related to the main institute are selected to participate in the registry. Twelve PICUs at children's hospitals and 11 general ICUs at critical care centres participate in the registry, and these cover for about $10 \%$ of the total ICU beds and $60 \%$ of PICU beds in Japan.

\section{Patient involvement}

Patients were not directly involved in the design of this study.

\section{Patients}

Consecutive patients aged $\leq 16$ years who had died in a PICU or ICU in a participating hospital during the study period between April 2014 (when JaRPAC was started) and March 2017 were included in this study. Neonatal patients who died at neonatal ICUs were excluded from the registry database.

\section{Study design}

This was a descriptive epidemiology study based on collected JaRPAC data. Data on paediatric deaths were extracted from the database, and patients were divided into two groups, namely those with a chronic condition (chronic group) and children without a chronic illness. The cause of death was registered and categorised as either an intrinsic or an extrinsic cause. The final diagnosis for the cause of death in the case of intrinsic disease was coded based on the International Classification of Diseases V.10 and categorised into one of nine groups, to ensure sufficient patients for analysis.
The groups comprised cardiovascular, respiratory, neuromuscular, congenital/genetic, gastrointestinal/ hepatobiliary-pancreatic, haematological/oncological, renal, sepsis and metabolic/endocrinological groups. Extrinsic causes of death were categorised as trauma, asphyxia or drowning.

The Paediatric Index of Mortality (PIM2) is used as a measure of severity. The PIM2 score is calculated from various coefficients determined by Slater et $a .^{20}$ The values used to calculate this score must result from the first face-to-face contact between patients and physicians at ICUs or PICUs. If data for some factors such as arterial blood gas sample were not obtained, these factors were not included in the PIM2 calculation. Patient survival was defined as discharge from an ICU or PICU.

Postoperative treatment admission was considered elective admission. Admissions from general wards or transfer from other hospitals due to urgent deterioration and need for higher quality intensive care, or from the emergency department (ED), were considered urgent admissions. The time of admission was divided into four categories: weekday daytime, weekday night, weekend daytime and weekend night. Holidays were dealt with as a weekend. The method of transportation was divided into four categories: via ambulance and escorted by a doctor; via helicopter and escorted by a doctor; via an emergency medical service; and others (eg, self-arrival).

We defined a chronic condition according to Feudtner et al $\mathrm{s}^{21}$ definition, which states that a chronic condition 'involves either several different organ systems or one organ system severely enough to require specialty paediatric care and probably some period of hospitalization in a tertiary care center'. Chronic conditions were grouped into nine organ systems (cardiovascular, respiratory, neuromuscular, congenital/genetic abnormalities, gastrointestinal, oncological, renal, metabolic/ endocrinological and haematological/immunological) based on Feudtner et al $\mathrm{s}^{21}$ complex chronic conditions. Children with multiple chronic conditions were counted in each group for the specific analysis but were only counted once in the overall analysis. A clinically dominant chronic condition was defined as 'the medical condition which carried the greatest morbidity for the child'. ${ }^{22}$

\section{Statistical analysis}

The age, length of PICU or ICU stay, and PIM2 data were clearly skewed, and medians with IQRs were used for numerical variables. Numerical variable differences between the two groups were compared using a MannWhitney $\mathrm{U}$ test. The $\chi^{2}$ test was used to compare frequencies in gender, urgent admission, time of admission, extrinsic cause of death and transportation methods. Data management and statistical analyses were undertaken using EZR software (Y Kaneda, Saitama, Japan). A $p$ value of $<0.05$ was considered statistically significant. 


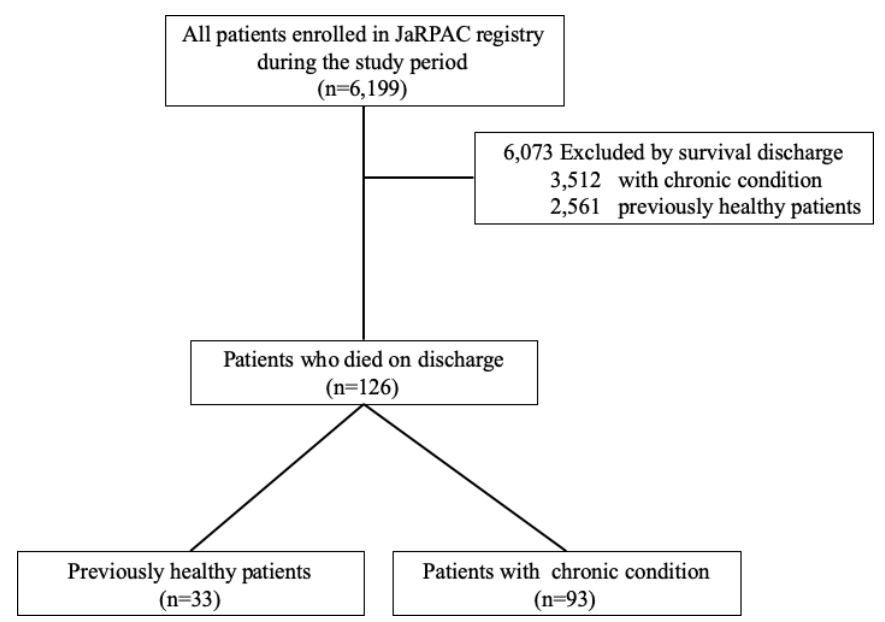

Figure 1 Study profile. JaRPAC, Japanese Registry of Pediatric Acute Care.

\section{RESULTS}

A total of 23 hospitals participated in the study, and 6199 paediatric patients had been registered in the JaRPAC database during the study period. Of the registered paediatric patients, 6073 survived and 126 (2.1\%) died during the study period. Among the patients who were discharged, $3605(58 \%)$ belonged to the chronic condition group and 2594 (42\%) to the group without a chronic illness (figure 1). Patient characteristics are shown in table 1 . Thirty-three children without a chronic illness $(1.3 \%)$ and 93 chronically ill patients $(2.6 \%)$ died $(p<0.01)$. There were no significant differences in age, gender, admission urgency, or median length of ICU or PICU stay between the two groups (table 1). The median PIM2 predicted per cent mortalities of all admissions were $1.1 \%(0.6-3.0)$ and $1.0 \%(0.3-3.2)$ in the group without chronic illness and in the group with chronic condition, respectively. The median PIM2 predicted per cent mortalities in patients who died were $93.5 \%$ and $48.2 \%$ in the group without a chronic illness and in the group with chronic condition, respectively. There was a statistically significant difference in the PIM2 predicted per cent mortalities in all admissions and in patients who died $(\mathrm{p}<0.01)$, mortality $(\mathrm{p}<0.01)$ and transportation methods $(p<0.01)$ between the two groups.

Table 2 shows the proportion of mortality among patients in ICUs or PICUs. Twenty-five paediatric patients died due to an extrinsic disease, and there was a significant difference in extrinsic diseases ( $45 \%$ vs $11 \%, \mathrm{p}<0.01$ ) between the two groups.

Table 3 lists the chronic conditions of patients. Twenty-seven patients had cardiovascular disease, which was the most common chronic condition, with congenital heart disease as the most frequent diagnosis $(22 / 27$,

Table 1 Characteristics of patients who died in ICU or PICU

\begin{tabular}{|c|c|c|c|c|}
\hline & $\begin{array}{l}\text { All deaths } \\
(\%)\end{array}$ & $\begin{array}{l}\text { Group without } \\
\text { chronic illness (\%) }\end{array}$ & $\begin{array}{l}\text { Group with chronic } \\
\text { illness } \\
(\%)\end{array}$ & $P$ value \\
\hline Characteristics & 126 & 33 & 93 & \\
\hline Age (months) & $19.5(5.25-96)$ & $12(4-116)$ & $20(6-83)$ & 0.87 \\
\hline Gender (male) & $76(60)$ & $18(55)$ & $58(62)$ & 0.82 \\
\hline Length of PICU/ICU stay (days) & $3(1-15.75)$ & $3(2-8)$ & $3(1-17)$ & 0.82 \\
\hline PIM2 predicted mortality (\%) & $66.6(15.5-94.7)$ & $93.5(77.1-98.5)$ & $37.7(9.5-92.1)$ & $<0.01$ \\
\hline Urgent admission & $117(93)$ & $33(100)$ & $84(90)$ & 0.14 \\
\hline Mortality (\%) & 2.1 & 1.3 & 2.6 & $<0.01$ \\
\hline \multicolumn{5}{|l|}{ Time of admission } \\
\hline Weekday daytime & $41(33)$ & $6(18)$ & $35(38)$ & \\
\hline Weekday night & $35(28)$ & $11(33)$ & $24(26)$ & \\
\hline Weekend daytime & $9(7)$ & $4(12)$ & $5(5)$ & \\
\hline Weekend night & $25(20)$ & $7(21)$ & $18(19)$ & \\
\hline No data & $16(13)$ & $5(15)$ & $11(12)$ & 0.27 \\
\hline \multicolumn{5}{|l|}{ Transportation methods } \\
\hline Ambulance with doctor & $38(30)$ & $17(52)$ & $21(22)$ & \\
\hline Helicopter with doctor & $3(2)$ & $3(9)$ & $0(0)$ & \\
\hline EMS & $38(30)$ & $13(39)$ & $25(27)$ & \\
\hline General ward or OR & $38(30)$ & $0(0)$ & $38(41)$ & \\
\hline Other & $9(7)$ & $0(0)$ & $9(10)$ & $<0.01$ \\
\hline
\end{tabular}

EMS, emergency medical service; ICU, intensive care unit;OR, operating room; PICU, paediatric intensive care unit; PIM2, Paediatric Index of Mortality 2. 
Table 2 Proportion of mortality among patients in the ICU or PICU

\begin{tabular}{lllll}
\hline & Total (\%) & $\begin{array}{l}\text { Group without chronic } \\
\text { illness (\%) }\end{array}$ & $\begin{array}{l}\text { Group with chronic } \\
\text { illness (\%) }\end{array}$ & P value \\
\hline Cause of death & 126 & 33 & 93 & \\
Extrinsic disease & $25(20)$ & $15(45)$ & $10(11)$ & $<0.01$ \\
Intrinsic disease & $101(80)$ & $18(55)$ & $83(89)$ & $<0.01$ \\
\hline
\end{tabular}

ICU, intensive care unit; PICU, paediatric intensive care unit.

$81 \%)$. Neuromuscular disease was the second most frequently noted condition, with epilepsy as the most frequently noted chronic disease $(14 / 22,64 \%)$.

Table 4 shows the final diagnoses in the group without a chronic illness. Fifteen patients $(45 \%)$ died due to extrinsic causes, most commonly asphyxia and multiple trauma, followed by drowning. For deaths due to intrinsic diseases, encephalitis or encephalopathy $(4 / 33,12 \%)$ was the most common reason for the death of a child without any chronic condition, followed by myocarditis $(3 / 33,9 \%)$. All cardiac arrests in patients in the group without chronic illness occurred preadmission.

Table 5 shows the final diagnosis of paediatric patients with chronic conditions. In contrast to the group without chronic illness, the number of patients with extrinsic causes of death was smaller. Eighty-three patients (89\%) died due to an intrinsic disease, and the main cause of death was congenital heart disease (14/93, 15\%), followed by sepsis $(13 / 93,14 \%)$.

\section{DISCUSSION}

This is the first multicentre study to identify the aetiology of childhood deaths based on clinical profiles in PICUs and ICUs in Japan. This retrospective study found that the principal causes of death in children without a chronic illness were intrinsic causes, such as encephalopathy or myocarditis. The rate of death due to extrinsic causes was higher in the group without a chronic illness than in the chronic group. Moreover, PIM2 and the number of

\begin{tabular}{lc}
\hline $\begin{array}{l}\text { Table } 3 \text { Chronic conditions in patients who died with } \\
\text { comorbidities }\end{array}$ \\
\hline Chronic condition & $\mathbf{n}(\%)$ \\
\hline Cardiovascular disease & $27(29)$ \\
\hline Neuromuscular disease & $22(24)$ \\
\hline Haematological/Immunological disease & $3(3)$ \\
Respiratory disease & $6(6)$ \\
$\begin{array}{l}\text { Gastrointestinal, hepatobiliary-pancreatic } \\
\text { disease }\end{array}$ & $5(5)$ \\
Renal disease & $4(4)$ \\
Metabolic/Endocrinological disease & $3(3)$ \\
Oncological & $5(5)$ \\
Congenital/Genetic abnormality & $17(18)$ \\
Others & $13(14)$ \\
\hline
\end{tabular}

patients transported via ambulance or via helicopter and escorted by a doctor were higher for patients without a chronic condition than for patients with a chronic condition.

The mortality rate in this study was $2.1 \%$, which is similar to the mortality rates in PICUs reported from other countries $(2 \%-3 \%)$, and our findings are consistent with other reports. ${ }^{9-13}$ Neuromuscular and cardiovascular diseases were the most common causes of death in critically ill paediatric patients with chronic disease. Typpo et al reported similar data, ${ }^{13}$ as did a study that involved PICUs in England, Wales and Scotland. ${ }^{19}$ However, the most common causes of death in children without a chronic illness were encephalopathy/encephalitis and myocarditis, and the mortality rate due to extrinsic causes in children without a chronic illness was significantly higher than that of the chronic group in our study.

Typpo et al reported that between $46 \%$ and $62 \%$ of patients admitted to a PICU have a chronic condition, ${ }^{13} 22$ which is in agreement with our observation

Table 4 Cause of death in patients without chronic illness

\begin{tabular}{lll} 
Diagnosis & $\begin{array}{l}\text { Total } \\
\text { patients (n) }\end{array}$ & $\begin{array}{l}\text { Cardiac } \\
\text { arrest (n) }\end{array}$ \\
\hline Extrinsic cause & 15 & \\
$\quad$ Asphyxia & 6 & 5 \\
Multiple trauma & 6 & 3 \\
$\quad$ Drowning & 3 & 3 \\
Intrinsic cause & 18 & \\
$\quad$ Neuromuscular disease & & \\
$\quad$ Encephalitis/Encephalopathy & 4 & 1 \\
$\quad \begin{array}{l}\text { Intracerebral haemorrhage } \\
\text { Cardiovascular disease }\end{array}$ & 1 & 0 \\
$\quad$ Myocarditis & 3 & 1 \\
Gastrointestinal, hepatobiliary-pancreatic disease \\
$\quad$ Hepatic failure & 1 & 1 \\
Infection & & \\
$\quad$ Sepsis & 1 & 1 \\
$\begin{array}{l}\text { Metabolic/Endocrinological } \\
\text { disease }\end{array}$ & & \\
$\quad$ Metabolic disorder & 1 & 0 \\
Unknown & 7 & 7 \\
\hline
\end{tabular}


Table 5 Final diagnosis in the chronic condition group

\begin{tabular}{|c|c|c|}
\hline Diagnosis & $\begin{array}{l}\text { Total } \\
\text { patients (n) }\end{array}$ & $\begin{array}{l}\text { Recovery } \\
\text { from CPA } \\
\text { (n) }\end{array}$ \\
\hline Extrinsic cause & 10 & \\
\hline Drowning & 4 & 4 \\
\hline Asphyxia & 3 & 3 \\
\hline Multiple trauma & 2 & 2 \\
\hline Traumatic brain injury & 1 & 1 \\
\hline Intrinsic cause & 83 & \\
\hline \multicolumn{3}{|l|}{ Cardiovascular disease } \\
\hline Congenital cardiac anomaly & 14 & 6 \\
\hline Cardiac myopathy & 6 & 3 \\
\hline Pulmonary hypertension & 2 & 1 \\
\hline Myocarditis & 1 & 0 \\
\hline \multicolumn{3}{|l|}{ Infection } \\
\hline Sepsis & 13 & 5 \\
\hline \multicolumn{3}{|l|}{ Neuromuscular disease } \\
\hline Encephalitis/Encephalopathy & 8 & 6 \\
\hline Neurological disorder & 2 & 1 \\
\hline \multicolumn{3}{|l|}{ Respiratory disease } \\
\hline Pneumonitis & 7 & 1 \\
\hline Pulmonary disease & 3 & 2 \\
\hline Bronchus obstruction & 2 & 2 \\
\hline \multicolumn{3}{|c|}{ Gastrointestinal, hepatobiliary-pancreatic disease } \\
\hline Gastrointestinal disease & 3 & 3 \\
\hline Hepatic failure & 1 & 0 \\
\hline \multicolumn{3}{|l|}{ Haematological/Oncological } \\
\hline Oncological disease & 2 & 1 \\
\hline \multicolumn{3}{|l|}{ Metabolic/Endocrinological disease } \\
\hline Metabolic disorder & 2 & 0 \\
\hline Unknown CPA & 17 & 17 \\
\hline
\end{tabular}

CPA, cardiopulmonary arrest.

that $58 \%$ of admitted patients had a chronic condition. Previous studies have reported cardiovascular disease as the most common chronic condition, followed by neuromuscular disease and respiratory problems, ${ }^{11} 13$ 22-24 and our study reported similar findings. After categorising chronic conditions, congenital cardiovascular disease was the most common, followed by neuromuscular disease. Similar reports have shown that in patients with a chronic condition who were admitted to the PICU, the most common chronic conditions were cardiovascular and neuromuscular diseases, which are accompanied by a high mortality rate. ${ }^{11} 1322$ In our study, the mortality rate was also significantly higher in the chronic condition group than in children without a chronic illness. After adjusting for illness severity, various studies have reported that having an increasing number of chronic conditions was associated with increasing odds of mortality. ${ }^{11} 192225$ Fonseca and Ferreira ${ }^{26}$ reported the performance of PIM2 with chronic conditions in Brazil and found that the increased mortality of patients with chronic conditions could not be verified by the probability of death estimated by PIM2. The similar probabilities between patients with and without chronic conditions may indicate poor score performances. ${ }^{26}$ Edwards $e t a l^{11}$ also reported that patients with chronic conditions had significantly higher risks of mortality in the PICU than that predicted by PIM2. ${ }^{11}$

The PIM2 score was developed in Australia and can be applied worldwide, although it is essential to test its performance in a large cohort in the country that intends to adopt it. The PIM2 score covers an intrinsic description of the healthcare system, PICU organisation and case-mix of the population that was used to create it. ${ }^{20}$ Imamura et $\mathrm{l}^{18}$ validated the performance of PIM2 in a population of paediatric patients who were admitted to PICUs in Japan. Although this was a single-centre, prospective cohort study, it was the largest PICU in Japan. This study reported useful receiver operating characteristic curves about PIM2 discrimination between survival and death, of which the c-index was 0.92 (95\% CI 0.89 to 0.96$).{ }^{18}$ Other prospective studies have reported the performance of PIM2 in other countries. ${ }^{20}$ 27-32 PIM2 showed good or excellent discrimination in these studies, but the calibrations varied by geographical location or healthcare organisation. Wolfer et al reported that PIM2 predicted per cent of injury or postoperative deaths was greater than that of actual deaths. ${ }^{27}$ In this study, PIM2 predicted per cent mortality in patients who died was statistically higher in children without a chronic illness than in those with chronic conditions. It is thought that in children without a chronic illness, there were more patients who had recovered from cardiopulmonary arrest (73\%), and these were considered high risk in the PIM2 calculation.

Finally, most children without chronic illness died from intrinsic diseases, but the mortality rate of extrinsic diseases is higher in paediatric patients with chronic conditions. The highest risk of mortality was from cardiovascular disease and from trauma or asphyxia, which indicates severe clinical courses.

There are several limitations to our study, despite the relatively large sample size. First, although the JaRPAC database is the largest available database for critically ill paediatric patients, it does not capture all PICUs and ICUs in Japan, and there may be a selection bias towards more academically focused or resource-rich PICUs and ICUs that were able to join JaRPAC. Moreover, this registry does not provide institutional characteristics and therapeutic levels. Second, JaRPAC is based on PICU or ICU settings; hence, data on hospital mortality or long-term follow-up were unavailable. We did not control for variations in the specific types of therapy administered in EDs or transportation prior to admission. Third, a patient's risk of mortality was assessed only through PIM2. This prediction model is intended for groups of patients but not individuals, and for individual patients this model 
may have misrepresented their actual risk of mortality. A new paediatric risk score for mortality (PRISM) or PIM3 method might better reflect mortality risk of patients in the future. ${ }^{33} 34$

\section{CONCLUSION}

This is the first report that used a registry of critically ill paediatric patients in Japan to describe the clinical profiles of critically ill paediatric patients who had died in PICUs or ICUs. The majority of deaths were in children with a chronic condition. The major cause of death in children without a chronic illness was due to intrinsic causes, such as cardiovascular and neuromuscular diseases, and the proportion of deaths due to extrinsic causes was higher in children without chronic illness.

Acknowledgements Data for this study were provided by JaRPAC, and I wish to thank its members. Hiroshi Tanaka provided critical review.

Contributors TI designed this study and analysed and interpreted the results. TI drafted the manuscript.

Funding The authors have not declared a specific grant for this research from any funding agency in the public, commercial or not-for-profit sectors.

Competing interests None declared.

Patient consent for publication Not required.

Ethics approval This study was approved by the Institutional Review Board (30-025) of Juntendo University Urayasu Hospital, Chiba, Japan, and the need for informed consent was waived.

Provenance and peer review Not commissioned; externally peer reviewed. Data availability statement No data are available.

Open access This is an open access article distributed in accordance with the Creative Commons Attribution Non Commercial (CC BY-NC 4.0) license, which permits others to distribute, remix, adapt, build upon this work non-commercially, and license their derivative works on different terms, provided the original work is properly cited, appropriate credit is given, any changes made indicated, and the use is non-commercial. See: http://creativecommons.org/licenses/by-nc/4.0/.

\section{REFERENCES}

1. Peltoniemi OM, Rautiainen $P$, Kataja J, et al. Pediatric intensive care in PICUs and adult ICUs: a 2-year cohort study in Finland. Pediatr Crit Care Med 2016;17:e43-9.

2. Fiser DH, Tilford JM, Roberson PK. Relationship of illness severity and length of stay to functional outcomes in the pediatric intensive care unit: a multi-institutional study. Crit Care Med 2000;28:1173-9.

3. Pearson G, Barry P, Timmins C, et al. Changes in the profile of paediatric intensive care associated with centralisation. Intensive Care Med 2001;27:1670-3

4. Shann F, Pearson G. Paediatric intensive care - specialisation reduces mortality. Anaesthesia 1999;54:809-10.

5. Pearson G, Shann F, Barry P, et al. Should paediatric intensive care be centralised? Trent versus Victoria. Lancet 1997;349:1213-7.

6. Pollack MM, Alexander SR, Clarke N, et al. Improved outcomes from tertiary center pediatric intensive care: a statewide comparison of tertiary and nontertiary care facilities. Crit Care Med 1991;19:150-9.

7. Pollack MM, Cuerdon TT, Patel KM, et al. Impact of quality-ofcare factors on pediatric intensive care unit mortality. JAMA 1994;272:941-6.

8. Verlaat $\mathrm{CW}$, Visser $\mathrm{IH}$, Wubben $\mathrm{N}$, et al. Factors associated with mortality in low-risk pediatric critical care patients in the Netherlands. Pediatr Crit Care Med 2017;18:e155-61.

9. Markovitz BP, Kukuyeva I, Soto-Campos G, et al. PICU volume and outcome: a severity-adjusted analysis. Pediatr Crit Care Med 2016;17:483-9.

10. Ibiebele I, Algert CS, Bowen JR, et al. Pediatric admissions that include intensive care: a population-based study. BMC Health Serv Res 2018;18:264.
11. Edwards JD, Houtrow AJ, Vasilevskis EE, et al. Chronic conditions among children admitted to U.S. pediatric intensive care units: their prevalence and impact on risk for mortality and prolonged length of stay*. Crit Care Med 2012;40:2196-203.

12. Edwards JD, Lucas AR, Stone PW, et al. Frequency, risk factors, and outcomes of early unplanned readmissions to PICUs*. Crit Care Med 2013;41:2773-83.

13. Typpo KV, Petersen NJ, Petersen LA, et al. Children with chronic illness return to their baseline functional status after organ dysfunction on the first day of admission in the pediatric intensive care unit. J Pediatr 2010;157:108-13.

14. Taylor A, Butt W, Ciardulli M. The functional outcome and quality of life of children after admission to an intensive care unit. Intensive Care Med 2003;29:795-800.

15. Jones S, Rantell K, Stevens K, et al. Outcome at 6 months after admission for pediatric intensive care: a report of a national study of pediatric intensive care units in the United Kingdom. Pediatrics 2006;118:2101-8.

16. Gullberg N, Kalzén $\mathrm{H}$, Luhr O, et al. Immediate and 5-year cumulative outcome after paediatric intensive care in Sweden. Acta Anaesthesiol Scand 2008;52:1086-95.

17. Namachivayam P, Shann F, Shekerdemian L, et al. Three decades of pediatric intensive care: who was admitted, what happened in intensive care, and what happened afterward. Pediatr Crit Care Med 2010;11:549-55.

18. Imamura $\mathrm{T}$, Nakagawa $\mathrm{S}$, Goldman RD, et al. Validation of pediatric index of mortality 2 (PIM2) in a single pediatric intensive care unit in Japan. Intensive Care Med 2012;38:649-54.

19. Hardelid P, Dattani N, Gilbert R, et al. Estimating the prevalence of chronic conditions in children who die in England, Scotland and Wales: a data linkage cohort study. BMJ Open 2014;4:e005331.

20. Slater A, Shann F, Pearson G, et al. Pim2: a revised version of the paediatric index of mortality. Intensive Care Med 2003;29:278-85.

21. Feudtner C, Feinstein JA, Zhong W, et al. Pediatric complex chronic conditions classification system version 2: updated for ICD-10 and complex medical technology dependence and transplantation. BMC Pediatr 2014;14:19.

22. O'Brien S, Nadel S, Almossawi O, et al. The impact of chronic health conditions on length of stay and mortality in a general PICU. Pediatr Crit Care Med 2017;18:1-7.

23. Dosa NP, Boeing NM, Ms N, et al. Excess risk of severe acute illness in children with chronic health conditions. Pediatrics 2001;107:499-504.

24. Odetola FO, Gebremariam A, Davis MM. Comorbid illnesses among critically ill hospitalized children: impact on hospital resource use and mortality, 1997-2006. Pediatr Crit Care Med 2010;11:457-63.

25. Simon TD, Berry J, Feudtner C, et al. Children with complex chronic conditions in inpatient hospital settings in the United States. Pediatrics 2010;126:647-55

26. Fonseca JGda, Ferreira AR. [Application of the Pediatric Index of Mortality 2 in pediatric patients with complex chronic conditions]. Pediatr 2014;90:506-11.

27. Wolfler A, Silvani P, Musicco M, et al. Pediatric index of mortality 2 score in Italy: a multicenter, prospective, observational study. Intensive Care Med 2007;33:1407-13.

28. Brady AR, Harrison D, Black S, et al. Assessment and optimization of mortality prediction tools for admissions to pediatric intensive care in the United Kingdom. Pediatrics 2006;117:e733-42.

29. Thukral A, Lodha R, Irshad M, et al. Performance of pediatric risk of mortality (PriSM), pediatric index of mortality (PIM), and PIM2 in a pediatric intensive care unit in a developing country. Pediatr Crit Care Med 2006;7:356-61

30. Eulmesekian PG, Pérez A, Minces PG, et al. Validation of pediatric index of mortality 2 (PIM2) in a single pediatric intensive care unit of Argentina. Pediatr Crit Care Med 2007;8:54-7.

31. Hariharan S, Krishnamurthy K, Grannum D. Validation of pediatric index of mortality-2 scoring system in a pediatric intensive care unit, Barbados. J Trop Pediatr 2011;57:9-13.

32. Mestrovic J, Kardum G, Polic B, et al. Applicability of the Australian and New Zealand paediatric intensive care registry diagnostic codes and paediatric index of mortality 2 scoring system in a Croatian paediatric intensive care unit. Eur J Pediatr 2005;164:783-4.

33. Pollack MM, Holubkov $\mathrm{R}$, Funai $\mathrm{T}$, et al. The pediatric risk of mortality score: update 2015. Pediatr Crit Care Med 2016;17:2-9.

34. Straney L, Clements A, Parslow RC, et al. Paediatric index of mortality 3: an updated model for predicting mortality in pediatric intensive care*. Pediatr Crit Care Med 2013;14:673-81. 